\title{
Psicomotricidade relacional: estratégia de intervenção pedagógica na educação
}

\author{
Ângela Adriane Schmidt Bersch ${ }^{1}$ \\ Eliane Lima Piske ${ }^{2}$
}

\begin{abstract}
Resumo: entrelaçar na pesquisa uma estratégia de intervenção pedagógica que seja capaz de apresentar influências na Educação Infantil e no Ensino Superior foi o mote do artigo. O objetivo da proposta foi apresentar uma estratégia pedagógica que potencializa o processo de aprendizagem e de desenvolvimento humano. A Psicomotricidade Relacional (PR) foi o mecanismo de intervenção nas pesquisas com crianças e estudantes de graduação, ambos no extremo Sul do Brasil. As sessões de PR na Educação Infantil e no curso de Licenciatura em Educação Física foram a tríade encontrada para construir pesquisas com as crianças e os adultos. O olhar por meio da teoria bioecológica apontam, na análise de dados, que as sessões de PR potencializam a imaginação, o faz de conta, a inventividade, a ludicidade, as relações, a organização, o planejamento, a reflexão, aspectos inerentes ao processo de aprendizagem e de desenvolvimento biopsicossocial. Portanto, trata-se de uma disciplina potente a ser ministrada no espaço do Ensino Superior para que o professor possa fazer uso desta no processo pedagógico no âmbito escolar, especialmente na Educação Infantil.
\end{abstract}

Palavras -chave: Psicomotricidade Relacional. Educação Infantil. Ensino Superior.

\section{Relational psychomotricity: pedagogical intervention strategy on education}

Abstract: Intertwine in the search a pedagogical intervention srategy that is capable of present influences in early Childhood Education and in Higher Education was the motto of the article. The purpose of the proposal was to present a pedagogical strategy that enhances the learning process and human development. The Relational Psychomotricity (PR) was the intervention mechanism in research with children and undergraduate students, both in the far South of Brazil. The sessions of PR in early Childhood Education and in the Physical Education Degree Course were the triad found to build research with children and adults. The look through the bioecological theory point, in data analysis, that the sessions of PR potentiate the imagination, the make believe, the inventiveness, the playfulness, the relationships, the organization, the planning, the reflection, inherent aspects to the

\footnotetext{
${ }^{1}$ Doutora e Mestre em Educação Ambiental pela Universidade Federal de Rio Grande - FURG. Graduada em Educação Física pela Universidade Federal de Pelotas - UFPel. Líder do grupo de pesquisa e estudos ECOINFÂNCIAS - infâncias, ambientes e ludicidade. Integrante do Centro de Referência em Apoio às Famílias - CRAF. Professora Adjunta do Instituto de Educação da Universidade Federal do Rio Grande - FURG, atua nos cursos de Educação Física, Pedagogia e Pós-graduação em Educação. E-mail: angelabersch @ mail.com

2 Doutoranda e Mestre em Educação Ambiental pelo Programa de Pós-Graduação em Educação Ambiental da Universidade Federal do Rio Grande- PPGEA/FURG. Pedagoga. Especialista em Educação Infantil pela Universidade Federal de Pelotas- UFPel. Bolsista da Coordenação de Aperfeiçoamento de Pessoal de Nível Superior- CAPES. Colaboradora do Centro de Referência em Apoio às Famílias- CRAF/FURG. Integrante do Grupo de Estudos Ecoinfâncias: infâncias, ambientes e ludicidade. Colaboradora do UEADSL: Plataforma de Eventos do Grupo Texto Livre pela Faculdade de Letras da Universidade de Minas Gerais. Email: e.nanny@hotmail.com
} 


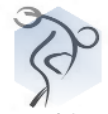

learning process and biopsychosocial development. Therefore, it's about a potent discipline to be ministered in Higher Education space so that the teacher can make use of this in pedagogical process in scope of the school, especially in early Childhood Education.

Keywords: Relational Psychomotricity. Childhood Education. Higher Education.

\section{RITO DE ENTRADA}

O artigo apresenta uma estratégia pedagógica potente na educação: a Psicomotricidade Relacional (PR). As relações entre as crianças e os adultos ocorrem nos lugares, nos espaços, nos contextos específicos, os quais se referem ao ambiente da sala de aula. Num primeiro momento, talvez pareça restrito, mas no decorrer da escrita defenderemos que não, pois dependerá da mobilização realizada e da estratégia metodológica escolhida.

Os lugares são contextos experienciais, onde os atores não são somente as pessoas que estão neles, mas os objetos que permeiam o espaço e compõem a natureza: pessoaambiente. Nesta linha tênue de reflexão e ação é que entra em cena a PR, como estratégia para compartilhar conhecimentos com as crianças e os adultos. Especialmente neste artigo, serão com crianças da Educação Infantil e adultos do Ensino Superior, tendo como objetivo investigar a contribuição da PR como mecanismo de intervenção nas pesquisas com as crianças e os estudantes de graduação, no extremo Sul do Brasil.

Estudos que tem como foco a psicomotricidade alertam para o envolvimento tanto do corpo como da mente nas ações e interações (LIMA, FERNANDES e ARAÚJO, 2015; AUCOUTURIER, 2010; FALKENBACH, 2003; VIEIRA, BATISTA e LAPIERRE, 2013). "O termo psicomotricidade foi mencionado pela primeira vez por Dupré, no começo do século XX, na França, como uma ciência que estuda o corpo em movimento, o homem e suas relações com seu mundo interno e externo" (KEPPELER; SARTORI, 2011, pp. 28-29). Sendo assim, o movimento pode ser de ordem individual ou coletiva quando se trata da Psicomotricidade Relacional, ou seja, destaca-se o aspecto da relação e os aspectos que dão suporte a evolução, ao desenvolvimento da socialização e da aprendizagem dos envolvidos (FONSECA, 2010). A criança utiliza o brincar como instrumento para compreender o mundo, bem como para revelar como se dá esta compreensão. Faz isso por meio de jogos simbólicos, sensório-motores, funcionais, lúdicos (GUTIERRES FILHO, 2003). 
A Psicomoticidade Relacional é uma estratégia de intervenção pedagógica que tem por base a possibilidade de (re) significar a aprendizagem ao possibilitar vivencias por meio de uma sistemática dialógica que permite experimentar as relações com materiais não estereotipados, com símbolos presentes no contexto ou construídos e com os demais colegas envolvidos, num espaço considerado sessão, em que todos os atores têm a oportunidade de conhecer a PR. As vivências na PR estimulam e contribuem sobremaneira para as atividades e tarefas motoras como correr, pular, rastejar, saltar, engatinhar, girar, equilibrar, entre outros (GALLAHUE e OZMUN, 2001; PISKE; BERSCH e YUNES, 2014). Reconhecemos a contribuição da PR para o desenvolvimento dos aspectos motores, entretanto, este não é o foco do nosso estudo. Queremos evidenciar neste artigo os aspectos psicomotores envolvidos e potencializados no decorrer dos encontros, conforme será apresentado a seguir:

\section{SENSIBILIZAR AO CONHECER: METODOLOGIA}

A estrutura das sessões de Psicomotricidade Relacional será apresentada numa sintonia interativa capaz de conhecer os participantes, assim como os ritos, materiais e os registros da PR. Como postulam Negrine (1995) e Falkenbach (2003), a sessão de Psicomotricidade Relacional é organizada com momentos de rituais que são: rito de entrada, sessão propriamente dita, sensibilização e rito de saída.

a) Rito de entrada: são feitas as combinações para favorecer a comunicação entre os participantes e o professor, momento em que as regras são combinadas.

b) Sessão propriamente dita: o professor tem um papel importante que é o de mobilizar, ao provocar uma reflexão das ações e variar os materiais que serão disponibilizados; ao pensar as quantidades e ao envolver os participantes na sessão.

c) Sensibilização e volta à calma: é o momento em que o participante relaxa e reflete sobre o que realizou na sessão. Pode-se neste momento utilizar som, massagem ou outras estratégias que favoreçam a volta a calma e a reflexão sobre as atividades e sensações percebidas no decorrer da sessão.

d) Rito de saída: espaço-tempo que oportuniza aos participantes comentar sobre as criações, vivências e o processo de escuta da prática psicomotriz dos demais envolvidos. Há, portanto, o tempo de escuta e o tempo de fala sobre si. 


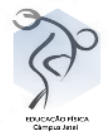

Vivenciando esta estrutura durante as aulas da disciplina Psicomotricidade Relacional, ofertada no Curso de Educação Física de uma Universidade Pública no Rio Grande/RS e com as crianças de uma Escola de Educação Infantil da rede pública do mesmo município. Os dados foram coletados por meio de observações, filmagens, relatos e anotações nos diários de campo. Para o registro de memoriais descritivos tanto os adultos quanto as crianças fizeram desenhos e compartilharam anseios, certezas $\mathrm{e}$ as expectativas compartilhadas no decorrer das sessões. Por falar em sessão, chegou o momento de apresentar os participantes ao conhecer os elementos das sessões da PR.

A pesquisa com o grupo de acadêmicos ocorreu na disciplina semestral de Psicomotricidade Relacional do curso de Educação Física, com carga horária de 30 horas/aula e com as crianças, aconteceu numa turma de Educação Infantil durante três meses, duas vezes por semana, totalizando 30 horas/aula. Participaram da pesquisa 30 estudantes na faixa de 20 a 47 anos do Curso de Educação Física, além de uma turma de Nível I da Educação Infantil, com 16 crianças de 4 a 5 anos. Seguimos os princípios éticos para a realização das pesquisas, em que tanto os adultos como as crianças foram convidadas a participar e ao aceitar, tanto os estudantes quantos os responsáveis pelas crianças, assinaram o Termo de Consentimento Livre e Esclarecido. Partimos da premissa que as crianças devem ser consultadas sobre seu interesse ou não, de participar de pesquisas. Assim, após diálogo com elas sobre os objetivos e importância do estudo, as crianças realizaram desenhos como forma de expressão simbólica para autorizar e validar sua participação na pesquisa. Todos os participantes concordaram com a divulgação dos relatos e das experiências compartilhadas coletivamente no decorrer das sessões de PR.

Os dados coletados nas pautas de observação, nos memoriais descritivos e nas filmagens foram analisados qualitativamente. Para a análise dos dados utilizamos a Grounded Theory (CHARMAZ, 2009). O método possibilitou a análise dos dados, do mesmo modo as categorias e subcategorias que emergiram a partir dos próprios discursos dos participantes, das anotações nas pautas de observações, dos memoriais descritivos, das expressões corporais nas filmagens (BAUER e GASKELL, 2008) e dos insights das pesquisadoras. O que está em consonância com a análise dos dados da PR, já que não perdemos as informações e a participação dos envolvidos na análise estará presente. 
Negrine (1995), um dos precursores da PR no Brasil esclarece que se trata de uma abordagem que oportuniza uma atitude ativa dos participantes, por meio de atividades lúdicas e dos jogos simbólicos em um ambiente seguro e prazeroso que é acompanhado por um e/ou mais professores. Vale mencionar que o corpo tem um lugar privilegiado, por permitir uma forma de comunicação particular de cada pessoa, em que exploram diversas possibilidades do fazer ao criar (PISKE, BERSCH e YUNES, 2014; JULIANO e BERSCH, 2015, LIMA; PISKE e BERSCH, 2018).

Negrine (1995) esclarece que a metodologia pode propiciar o exercício do pensamento por intermédio do planejamento, pela elaboração e o desenvolvimento de atividades concretas ao oportunizar vivências corporais concretas diversas e plurais, bem como a partir da mobilização do comportamento cooperativo entre os participantes. Sánchez, Martínez e Penalver (2003) relatam que as práticas psicomotoras precisam acompanhar a criatividade, o desenvolvimento e sensibilizar as pessoas no próprio percurso maturativo do ser pelo fazer, pela interação consigo, com os demais do contexto e com os objetos e símbolos presentes no contexto. Outro fator importante, como ensina Negrine (1995) é adotar uma atitude de escuta e de olhar atento, em virtude da disposição corporal pela interação nas atividades lúdicas e cooperativas. O professor precisa observar e acompanhar os participantes durante as sessões ao atuar no sentido de minimizar ou sanar os possíveis conflitos (MASETTO, 2003), ciente e de acordo com os autores:

É importante destacar que nosso estudo se faz no "espaço escolar", diferente de psicomotricidade relacional clínica e organizacional. No âmbito escolar, a professora se coloca mais como parceira para receber a não para dar, não somente com poder para ensinar, mas para aprender, conhecer e ajudar cada criança em seu processo de desenvolvimento do ser, do saber, do relacionar-se e inserir-se no mundo (CARVALHO; WAGNER; QUITETE, 2013, p. 71).

As aprendizagens potencializadas em uma sessão de PR não se restringem àquele momento. Visto que as aprendizagens ocorrem a partir das interações das pessoas com o meio externo e entre as pessoas, de forma interpsíquica, mas também intrapsíquica. Esta última pode ocorrer depois das sessões e é denominada de díade (BRONFENBRENNER, 1996). De forma prática, podemos tomar como exemplo um jogo ou uma brincadeira da qual a pessoa tenha participado durante uma sessão. As emoções provocadas a partir das interações com o 


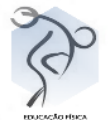

outro ou com o objeto podem fazer parte do pensamento desta por muito tempo. Este é o elemento construtor dos processos proximais, das díades (BRONFENBRENNER, 2011).

A PR propicia aos envolvidos ricos momentos e vivências diversas, tornando-as ativas frente a situações de conflito e possibilitando (re) ações sobre os possíveis prejuízos que os mesmos possam acarretar. Neste sentido, as atividades desenvolvidas nas sessões podem representar uma condição de proteção e favorecer aprendizagens significativas e melhores condições de desenvolvimento biopsicossocial. Olhar esta metodologia sob a ótica da teoria Bioecológica de Bronfenbrenner (2011) permite a confirmação da importância do mediador ou do psicomotricista que orienta, acompanha e potencializa as interações, com ela mesma, com seus pares, com os objetos e símbolos. E, sobretudo, sedimenta a ideia de que a Psicomotricidade Relacional pode ser um método promotor de aprendizagens significativas e de desenvolvimento bioecológico humano.

A PR caracteriza-se por escutar, considerar e potencializar o diálogo entre o corpo e os aspectos psíquicos do ser humano, focalizando na compreensão e na atividade dos núcleos psicoafetivos. A PR propicia um espaço de jogo espontâneo, incentivando as pessoas a manifestar e expressar as dificuldades relacionais, as necessidades e os desejos pela possibilidade de potencializar a socialização, ao sensibilizar pela comunicação simbólica da dimensão afetiva da prática psicomotriz educativa (JULIANO, et al., 2016).

A prática psicomotriz tem como eixo três alicerces que são: a comunicação, a exploração corporal e as vivências simbólicas, caracterizadas com o favorecimento do movimento espontâneo da pessoa e a estrutura das aulas promovendo a comunicação e a interação dos envolvidos (NEGRINE, 1995; PISKE; BERSCH e YUNES, 2014; LIMA, PISKE e BERSCH, 2018). O diferencial da prática psicomotriz educativa se situa na interação do adulto como mediador ao interagir e organizar a PR com estruturas pré-definidas; ao elaborar as atividades e as estratégias com o auxílio de diferentes materiais, a fim de favorecer a evolução comportamental pelo ser experiencial.

A PR neste estudo compreende a participação de crianças da Educação Infantil e de adultos do Ensino Superior pela possibilidade da prática psicomotriz no contexto das realidades educativas que se apresentam em cada um desses universos, mas que não são adversos. Podemos verificar a proximidade afetiva com a promoção de desenvolvimento 


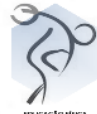

humano de crianças e de adultos com os resultados, conforme será apresentado no subitem a seguir:

\section{SESSÃO PROPRIAMENTE DITA: ANÁLISE E DISCUSSÃO}

Os instrumentos de registros foram aliados da coleta de dados na pesquisa, foram elas: pauta de observação, elaborada pela professora a partir dos comportamentos e das ações dos participantes durante as sessões de Psicomotricidade Relacional e o Memorial Descritivo, em que os participantes, nesta intervenção são: as crianças da Educação Infantil e os acadêmicos do curso de Educação Física, os quais registram suas percepções com relação aos sentimentos suscitados nas vivências, por meio de desenhos, das escritas, das pinturas, das esculturas, dentre outros artefatos. É importante nas sessões usar de várias estratégias como forma de registro, para explorar a criatividade, a inventividade e as diversas formas de expressão do ser humano.

Os ambientes das salas de aulas se transformavam em novos espaços para contemplar assim, a imaginação, o movimento, as expressões e as criações. Reiteramos que quando mencionamos contextos educativos, contemplamos tanto a Educação Infantil quanto o Ensino Superior, os quais abarcam os participantes desta investigação. Nos contextos foram disponibilizados diversos materiais não estereotipados, como: caixas de diferentes tamanhos e formas, tecidos, jornais, tampas, madeiras, espaguetes, potes, cordas, cones, garrafas pets, tampinhas, dentre outros. As crianças e os adultos têm forte imaginação e uma coisa ou objeto pode facilmente representar outra. Nesta interação ativa é imprescindível oportunizar a livre criação. Ela é suscitada pelos sentimentos e motivações internas de cada um. Esta é uma potente estratégia para que a pessoa possa passar de uma situação passiva diante de uma situação ou de um conflito interno para outra ativa onde ela, simbolicamente, resolve ou ameniza esses problemas (BERSCH e YUNES, 2017).

Nos contextos, os jornais ganharam outros significados, as folhas viraram pessoas, lagos, comidas, pontes, roupas e muito mais, assim como, por exemplo, os espaguetes que são usados em piscinas viraram espadas, cavalos e foram os próprios participantes que criaram as regras. Momento em que o cuidado com o outro e o ambiente merecem destaque, já que 


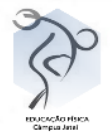

pensar no outro requer estar no lugar do outro, cuidando para não o machucar ao mesmo tempo em que atenta aos objetos. Desenvolver o senso crítico e de cuidado foi mencionado pelas crianças e pelos adultos como fundamental ao bem estarem âmbito planetário, conforme as palavras de João ${ }^{3}$ : "a lutinha não era permitida, agora podemos bater e cuidar" (diário de campo da Educação Infantil). O que vem ao encontro das palavras de Maria: "extravasar depois de um dia cheio, gastei minhas energias lutando e andando à cavalo" (diário de campo da graduação).

Por falar em aventura, as tampinhas e potinhos de diferentes tamanhos viraram personagens de uma história cheia de adrenalina. Do total de 46 participantes em ambos os contextos foram criadas aventuras e as histórias ganharam destaque a partir da imensa magia de criar ao fazer de conta e encontrar tanto os super-heróis, como a capacidade de abrir celas e soltar os pais que estavam privados de liberdade. Assim como os adultos esqueceram o dia estressante ao imaginar que estavam de férias e imaginaram os prazerosos desafios de uma viagem sem data de retorno. Com a breve explanação, percebemos a capacidade criativa das crianças e dos adultos a partir do uso de materiais extremamente simples, mas que não limitaram o imaginário.

No contexto do Ensino Superior é fundamental potencializar a articulação da PR à formação teórica, em que os participantes recebem artigos científicos. Numa discussão vivencial teórica os estudantes compreenderam corporal (mente) a dimensão da técnica bem como o aprofundamento com os textos sobre a temática. Possibilidade para que os acadêmicos no final da disciplina tenham um repertório teórico-prático e utilizem a metodologia da PR nos seus estágios curriculares obrigatórios, bem como enquanto profissionais da educação.

A oferta da disciplina para os graduandos do curso de licenciatura foi de grande relevância para transformar os contextos em espaços vivenciais. A Psicomotricidade Relacional pode ser uma forma de analisar e mobilizar os participantes a atentar a relação com as outras pessoas, os valores, as regras e adentrar a liberação do imaginário. Este último, segundo Lapierre e Lapierre (2010), é um mergulho no inconsciente ou semiconsciente do indivíduo, fazendo com que a caixa se torne um submarino, o bastão seja uma espada e assim,

${ }^{3}$ Os nomes dos participantes utilizados neste artigo são fíctícios para preservar o anonimato dos 


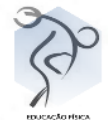

os objetos são para cada um a evocação de seus fantasmas ou uma forma de satisfazer seus desejos proibidos.

Chegamos à outra importante categoria, a proibição em fazer determinadas ações. Proibir conforme as crianças e os adultos é mobilizar o desejo em fazer, mesmo que muitas vezes as regras precisem ser burladas. Conforme Val: "sempre que escuto é proibido ai é que vou fazer" (diário de campo do Ensino Superior), já a criança Lorena desenha o que antes era proibido e agora pode, conforme podemos visualizar com o desenho a seguir:

Desenho 1: registro

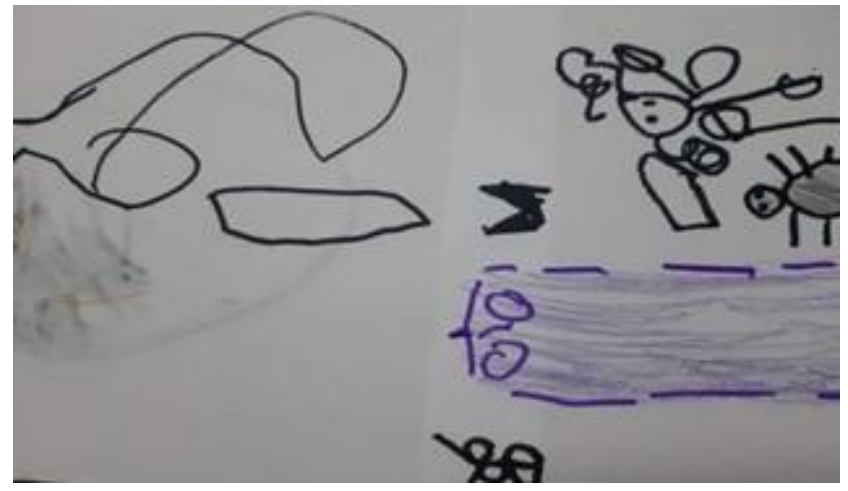

Fonte: dados das pesquisadoras, 2017.

Lorena com traços escuros desenha várias caixas no alto de um armário, logo elas todas jogadas no chão. As crianças e os adultos expressam que diferente das aulas dirigidas e com movimentos preestabelecidos, nas sessões de PR o improvável acontece, fato que possibilita uma maior riqueza de experiências. Estamos habituados a seguir ou imitar padrões de movimento e a proposta da PR é justamente permitir, aguçar e incentivar o participante a criar seu próprio movimento, sua brincadeira de forma individual ou em colaboração com o outro. Sobre isso Viera, Batista e Lapierre nos explicam que o movimento está conectado: "à percepção e à afetividade e se é um fator essencial ao desenvolvimento psíquico da criança e tem um papel importante nas suas relações com os outros, influencia igualmente no seu comportamento, tornando-se um fator de seu temperamento" (VIERA, BATISTA E LAPIERRE, 2013, p.16).

Vivemos numa sociedade em que um grande número de contatos é efetuado via artefatos culturais tecnológicos, em que as tecnologias fazem parte das aprendizagens, mas precisamos desafiar ao possibilitar novas atuações (PISKE, MADRUGA e GARCIA, 2019). 


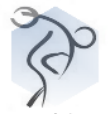

A PR proporciona as interações presenciais, as construções, às invenções e a imaginação individual ou em grupo, o que não é limitado pela interação física, mas permite explorar os contextos e experienciar os diferentes materiais. A regra que prevalece e que é combinada é retomada em cada encontro, que é o cuidado de si, do outro e dos objetos. Ou seja, podemos soltar a imaginação, desde que isto não machuque o outro e/ou ofereça risco ao jogar os objetos, por exemplo. O que vem ao encontro do que mencionam Carvalho, Wagner e Quitete:"Não se trata de permitir tudo, de liberar, mas de criar regras, negociar, criar vínculos para um viver juntos saudável e comprometido" (CARVALHO; WAGNER; QUITETE, 2013, p.74). Este é o grande plus da PR e por isso é uma estratégia pedagógica tão significativa para as diferentes faixas etárias.

Os graduandos, no processo de aquisição do conhecimento sobre a metodologia, ainda verbalizaram que diferentemente das aulas dirigidas e com movimentos, jogos e brinquedos preestabelecidos nas sessões de Psicomotricidade Relacional, o improvável muitas vezes acontece: “quem olha a aula de PR de fora acha que é a maior bagunça, mas quem está acompanhando percebe que todos estão desenvolvendo algo e que os aspectos psicomotores estão sempre envolvidos, mas sem aquela obrigada de fazer, ou de fazer por fazer como normalmente os alunos estão acostumados. Aqui a gente [os acadêmicos] aprende assim, brincando com os materiais, com os colegas, isto é muito positivo." (Tadeu, Diário de campo graduação).

A Psicomotricidade Relacional é entendida como jogo simbólico ou uma brincadeira em que as pessoas realizam ao vivenciar novas experiências no dia-a-dia. No marco relacional, o importante é trabalhar com o que a pessoa tem de positivo, com o que ela sabe fazer, e não se preocupar com o que ela não sabe. Conforme Negrine (1995), a melhor maneira para ajudar uma pessoa a superar suas dificuldades é conseguir que ela esqueça suas inabilidades.

A Psicomotricidade Relacional prioriza o brincar, o expressar livre e espontâneo, fato que leva muitos participantes a manifestarem diversos sentimentos e emoções: a agressividade, o medo, a afetividade, e outros aspectos inerentes ao desenvolvimento psicomotor. Conforme o acadêmico Jean: "eu me senti acolhido pelos colegas e me diverti muito e consegui pôr para fora o meu lado criança" (diário de campo da Graduação). O que 


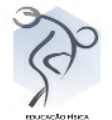

vem ao encontro das palavras da Joice: "ri tanto que doeu a barriga" (diário de campo da Educação Infantil).

Para estimular as diversas percepções sensoriais dos participantes foi necessário utilizar várias técnicas vivenciais. Sendo que em todos os encontros eram priorizadas atividades individuais, em duplas e/ou em pequenos grupos a partir de diversas questões para mobilizar o debate e as situações imaginárias. Vindo ao encontro das percepções dos participantes: "a metodologia ficou clara (...), pois a liberdade de realizar atividades trouxe a experiência de mudar a brincadeira para que ficasse mais prazerosa" (Joana, diário de campo da graduação). "(...) pude me transportar para a infância e às várias brincadeiras que eu fazia" (Luiz, diário de campo da graduação). Muitas vezes os educadores não têm conhecimento sobre a importância e o valor do brincar livre para o desenvolvimento psicomotor das crianças e dos adultos. De certa forma para alguns educadores o ato de brincar é apenas um passatempo, sem funções importantes, ou serve apenas para entreter a criança. Na visão das crianças da Educação Infantil, esse tempo para brincar ofertado nas sessões de Psicomotricidade Relacional foi uma maneira de assumirem vários papéis, quando contavam sobre as brincadeiras ou quando dialogávamos sobre o que estavam fazendo, as respostas eram: “(...) brincando de casas, a gente está fazendo comida para vender na lanchonete" (Diana). "Estamos fazendo uma cidade" (Bernardo), "apagando o fogo que está na casa, sou bombeiro" (Jonas).

O educador no âmbito da escola deve atuar como mediador ao compartilhar conhecimentos, ao possibilitar vivências. Neste sentido, durante as brincadeiras deve ser capaz de interpretar os jogos e as brincadeiras que as crianças e os adultos realizam sem ter a preocupação de julgar o mérito de suas ações. Portanto, é necessário acrescentar elementos a fim de propiciar momentos mais ricos de possibilidades para explorar os diferentes materiais.

Para essa compreensão da totalidade é imprescindível que os educadores passem pelas experiências, vivenciem-nas. A metodologia da PR é capaz de possibilitar o fazer ao interagir. Nesse sentido, chamamos a atenção para a fala da Joana: “(...) a disciplina está me fazendo pensar no quanto o comportamento das pessoas pode ser reflexo do nosso próprio comportamento, no caso, do meu (...) a proposta é me despir cada vez mais de pré-conceitos e me permitir vivenciar as situações em sua plenitude (diário de campo da graduação)". O que 


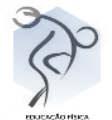

também ecoa nas palavras de Lívia: "vou curtindo os momentos e aqui têm de tudo, as casas, os cavalos, as espadas e meus amigos (...)".

Percebemos que através do ato de brincar, a criança se comunica com o mundo e o (re) constrói, assim como os adultos que (re) significam os acontecimentos. Quando brincamos, demonstramos os sentimentos, as angústias, as dificuldades e as habilidades. Vamos construindo nossas histórias a partir das vivências e da bagagem de mundo, aprendemos sem sequer saber que estamos aprendendo com o simples ato das brincadeiras, "podemos ser o que quiser", disse Gabriel (diário de campo da Educação Infantil). Não basta oferecer espaços físicos e os materiais para que as crianças realizem suas brincadeiras, é fundamental definir as pautas de intervenções pedagógicas para ajudar a criança a evoluir a partir da atividade lúdica. Para tanto, as pautas de observações são imprescindíveis no intuito de ser um instrumento de acompanhamento da evolução do processo de aprendizagem dos participantes (FALKENBACH, 2003). A seguir um relato da Jéssica:

“Analisando a atividade é interessante poder imaginar e interpretar já que é algo que não fazemos desde a infância. Vivenciar a fantasia dá uma ideia de como deve ser construtivo realizar estas atividades, pois a criança é livre nos seus movimentos, ela geralmente é mais livre nas suas ações" (diário de campo da turma de graduação). Sendo assim, estando no papel de observadores somos capacitados a desvendar incertezas que antes estavam ocultas, conforme Miguel: "estar no papel de observador foi algo novo para mim. Percebi a aula, os colegas, os movimentos de outro ângulo que nunca tinha visto antes. E achei superimportante e vou adotar na minha vida profissional como professor de Educação Física. Porque quando tu está dando a aula sem o olhar de observador é diferente, tem muitas coisas que você não enxerga e se enxerga não anota e depois esquece e pode ser fundamental para o desenvolvimento do aluno" (diário de campo da turma de graduação).

As práticas sustentadas nesta perspectiva nos permitem inferir com base nas observações que são realizadas e expressas nos mais delicados e singelos sentimentos. Nas sessões da PR as crianças apresentam além do esperado e para acolá do seu comportamento habitual, uma ação simbólica essencialmente social que precisa ser experienciada. Brincar com outras crianças é muito diferente de brincar somente com adultos, mas essas descobertas precisam ser realizadas pelas crianças e são elas que precisam contar ao expressar seus 


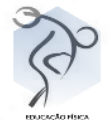

sentimentos. O brincar com diferentes materiais permite o improviso, envolve negociações e possibilita ser criativo nas construções.

O interagir nas sessões de PR permite que as crianças e os adultos tomem uma atitude ativa frente aos possíveis conflitos. A PR pode ser a única via de expressão da criança e do adulto, portanto, os educadores devem estar atentos à trajetória lúdica, visto que nesta, elas extravasam conflitos e demonstram os sentimentos, as necessidades, as carências, os desejos, as alegrias e as fantasias. É neste momento que o olhar atento e os registros das informações podem facilitar as intervenções ao potencializar o processo educativo.

Nos contextos percebíamos, por vezes, ao disponibilizar os materiais, que algumas crianças e adultos tinham uma postura autoritária frente às outras, muitas vezes egocêntricas. Algumas delas preferiam brincar sozinhas e outras eram excluídas do grupo quando tentavam se inserir nas brincadeiras. Outros preferiam sempre brincadeiras mais agressivas, situações em que era necessário intervir e refletir com os participantes a partir das suas ações. Assim, pensávamos juntos em outras maneiras de construções, evitando assim os conflitos ou agressões. Salientamos que os conflitos podem ocorrer, pois se trata de interações, contudo estes não podem machucar ou colocar em risco a integridade física dos participantes.

Quando o conflito ou a agressão ocorrem é necessário compreender a origem e a natureza das crises, e refletir junto com os envolvidos seus aspectos positivos e aceitar o confronto, sem atribuir-lhe caráter dramático. Nas sessões de Psicomotricidade Relacional, as crianças e os adultos precisam ter um espaço para manifestar sua agressividade no plano simbólico. Elas agridem e têm a oportunidade de defesa ao serem atacadas. Nesta perspectiva, o educador precisa construir um espaço relacional em que os elementos afetivos e emocionais estejam afetuosamente presentes, visto que favorecem a aquisição de conhecimentos e a construção da personalidade.

O ambiente educacional é um dos lugares constitutivo das pessoas, e, sobretudo, do viver. Os lugares são resultados de nossas interações e da profundidade de significados que atribuímos a eles ao experienciar, ao descobrir; são as pessoas que atribuem sentido ao seu lugar, seja ele físico ou subjetivo: é o sentir ao tocar. Tanto ao iniciar a vida escolar quanto ingressar no Ensino Superior, as crianças e os adultos precisam ter uma relação com o lugar 


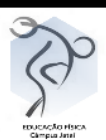

(escola-universidade), que sejam ricas de sentidos. Contribuindo assim para uma educação transformadora, rica em valores de respeito, solidariedade, sensibilização ecológica, relações sadias ao respeitar as diferenças e aprender a construir uma sociedade ecologicamente equilibrada em todos seus ambientes.

Com as reflexões entrelaçadas neste estudo, compreendemos que a Psicomotricidade Relacional contribui de forma significativa no que se refere ao desenvolvimento biopsicossocial. A participação por meio da PR pode proporcionar potentes mudanças e efetivas (trans) formações no desenvolvimento humano afetivo e relacional de adultos e crianças, por conseguinte, minimizar conflitos. Quando os participantes estão neste emaranhado relacional, tornam-se mais sensíveis, perceptíveis, atentos e criativos. Percebemos através dos relatos, que os participantes puderam ter esse olhar para si mesmo e para os outros. As sessões de Psicomotricidade Relacional na Educação Infantil e no Ensino Superior apresentaram dados para comprovar que a estratégia de intervenção pedagógica é potente na educação. 
Nas sessões, o corpo e as emoções têm espaços privilegiados na (trans) formação das pessoas, visto que por meio desta metodologia potencializa-se o desenvolvimento e a aprendizagem da pessoa, seja ela criança, adolescente, adulto ou idoso. Vale mencionar que através das relações afetivas, o que elas estabelecem com os outros, consigo mesmo e com os objetos possibilitam o desenvolvimento sócio afetivo e emocional. Desta forma, percebemos com mais clareza nosso lugar no mundo, bem como nosso papel social e a interação pessoaambiente numa permuta relacional.

A PR tem como foco a expressão corporal ao valorizar o jogo espontâneo e a comunicação não verbal, as potencialidades das pessoas, permitindo que elas manifestem livremente suas emoções. Além disso, valorizar e fortalecer o lado positivo ao provocar a autoestima pelo agir, interagir, refletir, reagir e superar possíveis dificuldades ao prospectar uma percepção mais positiva de si. Em suma, constatamos que a Psicomotricidade Relacional diante dos relatos e das considerações apresentadas neste artigo, torna-se aliada indispensável à (trans) formação permanente ao contribuir de forma significativa para a formação pessoal, profissional, mas, sobretudo na atuação com outras pessoas e em diferentes etapas da educação.

\section{CONSIDERAÇÕES FINAIS}

A Psicomotricidade Relacional tem uma estrutura definida: o rito de entrada que é o início, a sessão propriamente dita, o qual se trata do desenvolvimento e a sensibilização e rito de saída, que encerram a sessão. Seguir tal organização favoreceu o entendimento e a compreensão dos participantes ao vivenciar o todo, mas com a compreensão das partes, o que contribuiu sobremaneira para o processo pedagógico. Mencionamos que as sessões de PR potencializaram diversos aspectos da aprendizagem dos participantes, como: o planejamento, a organização, a manifestação de suas ideias, a escuta dos demais envolvidos, a resolução de conflitos, a reflexão, dentre outras características fundamentais ao desenvolvimento humano.

A PR é uma estratégia de intervenção pedagógica que facilita o acompanhamento do processo de aprendizagem dos participantes. Como já afirmamos a PR é organizada com estruturas de rotina que ajudam o professor na elaboração das atividades e nas estratégias, 


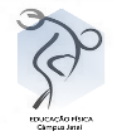

com o auxílio de diferentes materiais que favorecem a evolução no comportamento e no desenvolvimento psicomotor e biopsicossocial dos participantes.

O brincar foi um dos elementos fundamentais e fundantes no desenvolvimento humano mobilizado com a estratégia pedagógica, em especial, na infância, que é quando a criança constrói e edifica seus valores, suas crenças que podem vir a interferir e prospectar na imaginação, no faz de conta e na imensa magia de (re) criar. Sendo assim, apresentamos no artigo uma estratégia pedagógica capaz de envolver os professores, as crianças e os estudantes ao sensibilizar e potencializar os aspectos biopsicossociais. Encerramos esta sessão reafirmando a significativa contribuição da PR enquanto estratégia de intervenção pedagógica que pode (e deve) ser utilizada pelos professores no âmbito escolar. Para tanto, a PR é um recurso primordial ainda mais potente, se for ofertada como disciplina obrigatória nos currículos de formação de professores, em especial, das licenciaturas.

\section{REFERÊNCIAS:}

AUCOUTURIER, Bernard. O método Aucouturier: fantasmas de ação e prática psicomotora. São Paulo: Idéias e Letras, 2010. [ L Links ]

BAUER, Martim .W. ; GASKELL, George. Pesquisa Qualitativa com o texto imagem e som: um manual prático. RJ: Vozes, 2002.

BERSCH, Angela A.S. e YUNES, Maria A.M. O Brincar na pediatria hospitalar: análise bioecológica da saúde ambiental. Verlag Editora: Novas Edições Acadêmicas, 2017.

BERSCH, Ângela Adriane Schmidt; JULIANO, Andreia da Costa. Psicomotricidade relacional e a repercussão na formação acadêmica de alunos de educação física - FURG.

Revista Didática Sistêmica. Edição Especial, 2015. Disponível em: https://periodicos.furg.br/redsis/article/view/5906/3649. Acesso: 13 jun. 2019.

BRONFENBRENNER, Urie. Bioecologia do Desenvolvimento Humano: tornando os seres humanos mais humanos. (A. de Carvalho-Barreto Trad.).Porto Alegre: Artmed. 2011.

CARVALHO, Luzia Alves; WAGNER, Liliana Azevedo Nogueira; QUITETE, Tatiana Moço Carvalho. O corpo e o universo lúdico no desenvolvimento de habilidades essenciais no processo de letramento e alfabetização. Perspectivas Online: humanas. \& sociais aplicadas, Campos dos Goytacazes 7 (3), 69-78, 2013. Disponível em: https://www.seer.perspectivasonline.com.br/index.php/humanas_sociais_e_aplicadas/article/v iew/21/15. Acesso: 23 jul. 2019. 


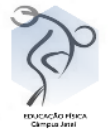

CHARMAZ Kathy. A construção da teoria fundamentada: guia prático para análise qualitativa. Porto Alegre: Artmed; 2009.

FALKENBACH, Atos. Prinz.. Um estudo de casos: as relações de crianças com síndrome de down e de crianças com deficiência auditiva na psicomotricidade relacional. 2003. 448 f. Tese (Doutorado em educação) - Faculdade de educação física, Universidade Federal do Rio Grande do Sul, Porto Alegre, 2003.

FERNANDES, Jorge. M.G.A.; GUTIERRES FILHO, Paulo.J.B.; REZENDE, Alexandre L.G. Psicomotricidade, jogo e corpo-em-relação: contribuições para a intervenção. Cadernos Brasileiros de Terapia Ocupacional. vol.26 no.3 São Carlos July/Sept. 2018. http://dx.doi.org/10.4322/2526-8910.ctoen1232

FONSECA, Vitor da. Psicomotricidade: uma visão pessoal. Construção Psicopedagógica, São Paulo, v. 18, n. 17, p. 42-52, 2010. Disponível em: 〈http://pepsic.bvsalud.org〉. Acesso em: 10 set. 2016. [ Links ]

GALlAHUE, David; OZMUN, John. Compreendendo o desenvolvimento motor. São Paulo: Phorte, 2001.

GUTIERRES FILHO, Paulo J.B.. A psicomotricidade relacional em meio aquático. Barueri: Manole, 2003. [ L Links ]

JULIANO, Andreia da Costa; BERSCH, Angela Adriane Schmidt; PISKE, Eliane Lima; GARCIA, Narjara Mendes; COUSIN, Claudia da Silva. Psicomotricidade relacional na educação infantil: relações de pertencimento e reflexões com a educação ambiental. Revista Eletrônica Mestrado em Educação Ambiental. E-ISSN 1517-1256, v. 33, n.3, p. 198-212, set./dez., 2016. Disponível em: https://periodicos.furg.br/remea/article/view/5832/4166. Acesso: 10 jun. 2019.

KEPPELER, Daiane da Rocha; SARTORI, Rodrigo Flores. As contribuições de Winnicott para a Psicomotricidade Relacional. Cinergis - Vol 12, n. 1, p. 25-32 Jan/Jun, 2011. Disponível em: file:///C:/Users/Eli/Desktop/pesquisaPSICORELACIONAL/1960-9438-1PB.pdf. Acesso: 18 jul. 2019.

LAPIERRE, André. AUCOUTURIER, Bernard. Fantasmas corporais e prática psicomotora. São Paulo: Manole, 1984.

LAPIERRE, André. A educação psicomotora na escola maternal. São Paulo: Manole, 1986.

LAPIERRE, André; LAPIERRE, Anne. $O$ adulto diante da criança de 0 a 3 anos: psicomotricidade relacional e formação da personalidade. Curitiba: Ed.UFPR: Criar, 2010. 


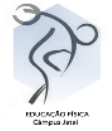

LIMA, Telma Ribeiro; PISKE, Eliane Lima; BERSCH, Angela Adriane. Estratégias cooperativas no contexto de acolhimento institucional: psicomotricidade relacional e massagens para bebês. In: Acolhimento institucional de crianças e adolescentes: organização de Lília Iêda Chaves Cavalcante... [et al.]. Curitíba: Juruá, 2018.

LIMA, Gleci M.M.; FERNANDES, Jorge M.G.A.; ARAÚJO, Luiza E.B.A. Psicomotricidade e psicanálise: a linguagem faz corpo. In: FERNANDES, J.M.G.A; GUTIERRES FILHO, Paulo J.B. (Org.). Atualidades da prática psicomotora. Rio de Janeiro: Wak, 2015. p. 105121.

MASETTO, Marcos T. Competência pedagógica do professor universitário. São Paulo: Summus, 2003.

NEGRINE, Airton. Aprendizagem e desenvolvimento infantil - Simbologia e jogo. Porto Alegre: Ed. Prodil, 1994a.

NEGRINE, Airton. Aprendizagem e desenvolvimento infantil - Perspectiva psicopedagógicas. Porto Alegre: Ed. Prodil, 1994b.

NEGRINE, Airton. Aprendizagem e desenvolvimento infantil - Psicomotricidade: alternativas pedagógicas. Porto Alegre: Ed. Prodil, 1995

PISKE, Eliane Lima; BERSCH, Angela Adriane Schmidt; YUNES, Maria Angela Mattar Yunes. Psicomotricidade Relacional com crianças e adolescentes da periferia do município de Rio Grande/RS. Anais. II Simpósio Luso-Brasileiro em Estudos da Criança - Pesquisa com Crianças: Desafios Éticos e Metodológicos, 2014. Disponível em:https://docplayer.com.br/5940906-Psicomotricidade-relacional-com-criancas-eadolescentes-da-periferia-do-municipio-de-rio-grande-rs.html. Acesso: 23 jul. 2019.

PISKE, Eliane Lima; MADRUGA, Elisângela Barbosa; GARCIA, Narjara Mendes.Estágio de docência semipresencial e as tecnologias digitais: conexões possíveis. In: anais VIII Congresso Internacional de Educação. fapas.edu.br/congresso | fapas.edu.br/revistas/anaiscongressoie Santa Maria, RS, Brasil, 2019. Disponível em: file://C:/Users/Eli/Downloads/1263-4638-1-PB\%20(1).pdf. Acesso: 23 jul. 2019.

SÁNCHEZ, Pilar; MARTÍNEZ, Marta; PENALVER, Iolanda. A Psicomotricidade na Educação Infantil: uma prática preventiva e educativa. Porto Alegre, RS: Artmed, 2003.

VIEIRA, José L.; BATISTA, Maria I. B.; LAPIERRE, Anne. Psicomotricidade relacional: a teoria de uma prática. Fortaleza, CE: RDS Editora, 2013. 